\title{
The anchoring effect-long-term dormancy and genetic population structure
}

\author{
Lisa Sundqvist ${ }^{1} \cdot$ Anna Godhe $^{1} \cdot$ Per R. Jonsson ${ }^{2} \cdot$ Josefin Sefbom $\mathbb{1}^{1,3}$
}

Received: 1 September 2017 / Revised: 18 May 2018 / Accepted: 11 June 2018 / Published online: 1 August 2018

(c) International Society for Microbial Ecology 2018

\begin{abstract}
Understanding the genetic structure of populations is key to revealing past and present demographic and evolutionary processes in a species. In the past decade high genetic differentiation has been observed in many microbial species challenging the previous view of cosmopolitan distribution. Populations have displayed high genetic differentiation, even at small spatial scales, despite apparent high dispersal. Numerous species of microalgae have a life-history strategy that includes a long-term resting stage, which can accumulate in sediments and serve as refuge during adverse conditions. It is presently unclear how these seed banks affect the genetic structure of populations in aquatic environments. Here we provide a conceptual framework, using a simple model, to show that long-term resting stages have an anchoring effect on populations leading to increased genetic diversity and population differentiation in the presence of gene flow. The outcome that species with resting stages have a higher degree of genetic differentiation compared to species without, is supported by empirical data obtained from a systematic literature review. With this work we propose that seed banks in aquatic microalgae play an important role in the contradicting patterns of gene flow, and ultimately the adaptive potential and population dynamics in species with long-term resting stages.
\end{abstract}

\section{Introduction}

In the absence of restricting factors, individuals of the same species will presumably mate randomly and gene flow will homogenize the gene pool. However, a multitude of factors and mechanisms can restrict gene flow thereby leading to partly isolated subpopulations (genetic structure) [1]. Assessment of population and landscape genetic structure is a key component in revealing the past and present

Electronic supplementary material The online version of this article (https://doi.org/10.1038/s41396-018-0216-8) contains supplementary material, which is available to authorized users.

$\square$ Josefin Sefbom

josefin.sefbom@marine.gu.se

1 Department of Marine Sciences, University of Gothenburg, Box 461, Göteborg, SE 40530, Sweden

2 Department of Marine Sciences - Tjärnö, University of Gothenburg, Strömstad, SE 45296, Sweden

3 Department of Biology, Laboratory of Protistology and Aquatic Ecology, Ghent University, Krijgslaan 281-S8, Gent B-9000, Belgium demographic and evolutionary processes that act on a species $[2,3]$. The degree of structure is highly influenced by past and present gene flow within a species' habitat $[4,5]$.

Free-living microscopic organisms have in the past been considered to have few limits to dispersal [6,7], and as a consequence should also share a common gene pool. However, since the development of high-resolution DNA fingerprinting (e.g. microsatellites, amplified length polymorphisms, and more recently high-throughput sequencing based techniques), population genetic studies on microorganisms have strongly challenged this view [8-10]. One group which falls into this category of high dispersal potential yet with apparently limited gene flow is aquatic eukaryotic microalgae [11-14]. Multiple population genetic studies have revealed a high degree of endemism within several microalgal species, yet low levels of genetic differentiation have also been observed in other species [15]. The degree of population genetic structure, as well as the spatial and temporal extent, varies greatly between species. This may not be surprising considering the prevalent diversity of microalgae, comprising a variety of phylogenies, ecology and reproductive strategies [16]. Nevertheless, a number general driving forces have been coupled to patterns of gene flow, e.g. geographic distance, ocean 
circulation patterns [11,17], local adaptation $[18,19]$ and founder events [20].

Several of those species where populations exhibit endemism (e.g. Alexandrium minutum [21], Ditylum brightwellii [13], Skeletonema marinoi [22], share the ability to form resting stages. Microalgae alternate between different life-history phases with mainly asexual proliferation, intermittent sexual reproduction, and some also form resting stages [23]. In the resting stage (also often referred to as quiescent phase, dormant stage, spore or cyst) cell division ceases and the cells enter a stage wherein the metabolic rate is drastically reduced [24]. The resting stage can be produced either sexually or asexually. Entering this stage is generally regarded as a form of refuge during adverse conditions for growth (e.g. light limitation or nutrient depletion), that can subsequently resume vegetative cell growth when conditions once again improve [25]. The formation of resting stages is however not a universal feature in this group and some resting stages are only temporary, whereas others can remain viable in sediments for as long as a century $[22,26]$.

The formation of resting stages is by no means limited to microalgae but is also found in e.g. bacteria [27], zooplankton [28], insects [29] and plants [30]. In higher plants the evolutionary role of seed banks has long been recognized as homogenizing between population genetic differentiation and enhancing genetic diversity [31-33]. Especially in a changing environment the seed banks will represent a gene pool of differently adapted alleles that maintain genetic polymorphisms [34], resulting in enhanced genetic diversity. This mechanism, termed the storage effect, was first described to explain the coexistence of competing species [35]. Recruitment of dormant propagules can then provide active populations with alleles, thus generating gene flow from the past [33]. In zooplankton the presence of dormant stages has been described as slowing down the rate of evolution by buffering against genetic change when under strong selection [36]. Boileau, Hebert [37] later described the same buffering mechanism of dormant stages as maintaining gene frequency divergence after founder events. Ultimately dormant stages can be viewed as either slowing down evolution when under directional selection [36] or enhancing evolution by archiving genetic variants when under fluctuating selection [28].

It has been proposed for organisms with large population sizes and rapid population growth that they possess the potential to quickly develop locally adapted populations and monopolize resources after founder events [38]. In the Monopolization hypothesis [38] the role of dormant stages is recognized as a buffering mechanism similar to that described by Boileau, Hebert [37] whereby migration between present day populations is diluted by 'migration from the past'. In microalgae, especially marine species, it is presently unclear how these seed banks affect the genetic structure of populations. Here we have explored the effect of resting stage formation on micro-evolutionary processes in microalgae with the hypothesis that 'migration from the past' will decrease the effect of gene flow in the system and enhance genetic diversity compared to similar microalgae that do not include a resting stage.

To address the contradicting patterns of often but not always limited gene flow observed in microalgae (marine and freshwater species), and where the underlying mechanisms remain ambiguous [39], we propose that the presence or absence of resting stages in aquatic microalgae may play an important role. Our rational is that local seed banks have an 'anchoring effect' leading to increased population genetic diversity and genetic structure. To illustrate this, a simple genetic population model was formulated that considers different degrees of re-seeding from historic populations (temporal gene flow) and a range of migration rates (spatial gene flow) in the presence or absence of a resting stage life-history strategy. Ultimately the objective was to explore the influence of resting stages with respect to population genetic diversity and genetic structure, under a range of different settings, by comparing a strategy with no resting stages versus one with resting stages. In addition we performed a systematic literature review and compiled empirical data on population genetic diversity (allelic richness) and genetic differentiation, for a wide range of microalgal species, in order to validate our results. Although our model was motivated by the inconsistent population genetic patterns observed between microalgal species, we aimed to keep the model as simple and general as possible in order to draw more general conclusions about the effect of resting stages in the context of similar biological systems.

\section{Material and Methods}

We constructed a model that allowed us to simulate the relative time to fixation for an allele in a population with resting stages versus one without resting stages. For the purpose of constructing a more qualitative and general model, important evolutionary processes such as mutation and selection were omitted as these will be highly specific to the system considered (e.g. species, environment, genetic marker). Using this model we specifically compared estimates of genetic diversity between the two life-history strategies. It is expected that reseeding from the sediment will slow down the loss of genetic diversity. This effect of resting stages on genetic diversity is illustrated in the onepopulation model and is primarily included to demonstrate the full picture of the processes. The effect of resting stages 
Fig. 1 A conceptual overview of the model for a species without resting stages (top panel), in each season ten random alleles are drawn, with replacement, from the previous bloom. When resting stages are included (lower panel) resting stages accumulate in season-specific layers in the sediment and a new active population is picked randomly from last year's bloom and from the sediment. In this example $30 \%$ of the new population is re-seeded from the sediment and the resting stage have a lifespan of 10 seasons. Color-coded boxes represent different alleles

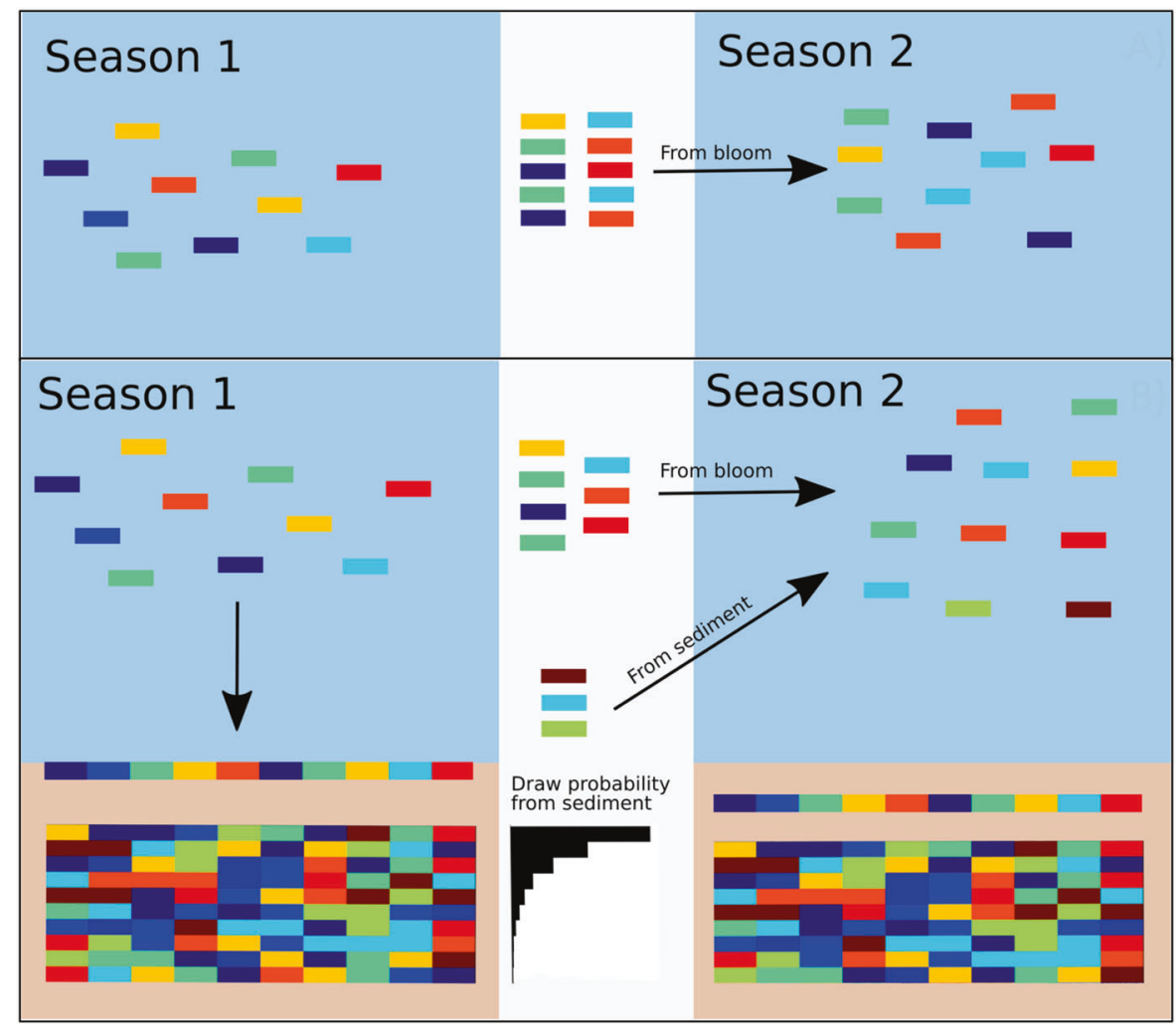

on genetic differentiation is modelled using two populations linked together through migration, below referred to as the two-population model. Both models include a scenario with no resting stages and a number of scenarios that varied in the contribution of resting stages to allele dynamics. These simplistic models are based on sequences of random draws.

Microalgal blooms are known to have very large population sizes, and therefore sampling with replacement was used to mimic the effect of alleles being randomly re-seeded from an infinitely large population. When sampling with replacement, the distribution of the sampled alleles was independent of the sample size but depended on the distribution of alleles in the pool from which it was sampled. It should therefore be emphasized that increasing the starting population size also increases the time to fixation and thus the results should be evaluated in a qualitative manner. In nature, where populations are immense, the time to fixation is likely considerably longer than in our modelled system. The effect of random genetic drift, and time to fixation of an allele, is highly dependent on the starting population size (proportional to $1 / \mathrm{Ne}$ per generation), however effective population sizes for microorganisms are poorly known. Similarly, the occurrence of intermittent sexual events varies between species and little is known about the frequency. To deal with these unknowns we chose to consider each allele as a separate entity in the model.

\section{One-population model}

An active population was initiated by drawing (randomly with replacement) 80 alleles from a starting distribution of 20 unique alleles. Seasons were used as the time unit, the end of one season and the beginning of next season is illustrated as a new set of (80) randomly drawn alleles. Because selection is not included and we sampled with replacement, the population size in the model was stationary as increasing the amount of alleles would not affect the distribution of alleles and hence not affect the result. In simulations without resting stages the sequence of vegetative populations was sampled by picking 80 alleles from the previous season's population. When resting stages were included different fractions of the 80 alleles were sampled, with replacement, from the seed bank. These sequences of random draws simulated the changes in allele frequencies over time (genetic drift).

For each simulation we recorded the number of seasons it took for one allele to reach fixation. Each parameter combination was simulated 1000 times and the mean number of seasons until fixation was calculated together with a $95 \%$ confidence interval. The model was also evaluated for different sizes of the pool of alleles initiating the bloom and the number of unique alleles. A conceptual overview of the model is illustrated in Fig. 1, where the upper and lower 
panels show the model without resting stages, and the model when resting stages are included, respectively.

The seed bank was built up by permitting all the alleles in the active planktonic population to accumulate in the sediment at the end of each season and form a seasonspecific layer, reflecting the proportion of alleles in the active population. The next active population was then initiated with a fraction of the population being generated from the resting stages in the sediment. With time, the contribution of alleles from resting stages of older blooms to the next active population decreases as they get buried under more recent blooms. Alleles were therefore sampled, with replacement, from the seed bank with probabilities generated from an exponentially decreasing function determining a high probability to sample alleles from the top of the seed bank and a decreasing probability for deeper layers in the sediment. The proportion of re-introduced alleles from the benthic seed-bank is likely to be dependent on several factors, e.g. benthic substrate characteristics, water depth, bioturbation and the time-span resting stages remain viable [40]. Because little is known about these factors, and they are also likely to vary greatly, both between different systems and different species, we tested the model under a wide range of scenarios. The model was simulated with $0,5,10,2550$ and $75 \%$ of alleles sampled from the sediment, zero representing a life-history strategy without resting stages. The model was also simulated with different life spans of the resting stages $(0,10,20,40,80$ and 120 seasons), again zero representing a life-history strategy without resting stages. In the simulation where different percentages of alleles were sampled from the sediment, the lifespan of resting stages was set to 20 seasons. In the simulation wherein we explored different lifespans of the resting stages, the percentage of alleles sampled from the sediment was set to $25 \%$. The longer the resting stage remained alive, the greater number of seasons were included in the seed bank. To keep the curve of the exponential function adjusted to changes in the number of historic seasons included in the seed bank, the rate of decay $(k)$ in the exponential function was changed $(0,0.6,0.3,0.15$, $0.075,0.05)$ together with the lifespan of the resting stage so that the probability to include half of the available layers was constant.

\section{Two-populations model}

To investigate the effect of the two different life-history strategies (resting stages and no resting stages) on genetic differentiation we connected two one-population models by symmetric migration. The two populations were initially completely differentiated meaning that model simulations commenced by sampling from two different sets of 20 unique alleles. Migration between the populations was modelled by letting a certain proportion of alleles from each population replace an equal number of local alleles. As described in the one-population model, the subsequent bloom was generated by sampling from the previous season's populations, which in the two-population model also included migrant alleles. After each migration event the active populations that formed resting stages sedimented and formed local seed banks consisting of local alleles and migrant alleles. The subsequent populations were initiated with different proportions coming from the seed bank, with $0 \%$ representing no resting stage formation (as described above). The model was simulated 1000 times for both lifehistory strategies. For each simulation and every season genetic differentiation Jost's D [41] was calculated between the two populations, presented as the mean along with a 95\% confidence interval. Because our model neglects mutations no new alleles arose and thus due to genetic drift the number of alleles naturally decreased over time, as populations became fixed for certain alleles. For this reason the use of Jost's D was favoured over the traditional $F_{\text {st }}$ or $\mathrm{G}_{\mathrm{st}}$ as an index of genetic differentiation as $\mathrm{D}$ is independent of genetic diversity [41]. Changes in genetic differentiation were evaluated for three different migration rates 1,5 and $20 \%$ per season. The impact of resting stages was evaluated for low (5\% 10 seasons) medium (25\% 40 seasons) and high (75\% 120 seasons) sediment contribution. The model was also evaluated for different initial sizes (i.e. number of alleles sampled to initiate a new bloom). The model was constructed in MATLAB (v. R2012b MathWorks Inc) and the code for running the simulations included in this study can be found at a Github repository https://github.com/lisa sundqvist/restingstages.

\section{Systematic literature review}

A systematic literature review was performed with the objective to evaluate whether our model qualitatively reflected empirical observations. Although real populations are exposed to many of the processes that we neglected in our model system, we were nevertheless curious to investigate whether a similar pattern of diversity and differentiation could be found in published data. We searched the Web of Science ${ }^{\mathrm{TM}}$ (Thomson Reuters) for articles including any of the following words: protist, diatom, dinoflagellate, coccolitophore, raphidophyceae, microalgae or phytoplankton. In order to acquire as many comparable studies as possible we chose to focus on those using microsatellite markers as these are, to date, the most widely used genetic markers for population genetic studies [42]. The search was refined by searching for articles containing any form of the word microsatellite*, which resulted in 146 articles (performed in May 2016). If an article reported on symbiotic species it was excluded. Each studied species was 
categorized as either having a resting stage or not. For three of the species included in the analysis the available literature is not conclusive on whether resting stages occur or not. Karenia brevis has been suggested to form resting cysts [43], however observation of naturally occurring cysts have never been reported and [44] and are therefore not considered an important survival strategy in this species. In this study $K$. brevis was categorizes as not forming resting stages. Oxyrrhis marina has been thought not to form resting stages [45] however they may form thin-membrane covered cysts [46]. Oxyrrhis marina is in this study categorized as not forming resting stages. Pseudo-nitzschia species has not been found to germinate from sediments in areas where Pseudo-nitzschia species were abundant in the planktonic community $[47,48]$. With the exception of one study [49] resting stages have not been reported in either sediment or laboratory studies for Pseudo-nitzschia species and was thus categorized as not forming resting stages.

\section{Exploring genetic diversity}

In the one-population model we investigated the time for one allele to reach fixation with and without resting stages, and as a consequence a loss in genetic diversity (measured as allelic richness). To assess whether a species' ability to form resting stages has a significant impact on genetic diversity in real populations we collected microsatellite data from published work on a range of microalgae species. In order to omit bias caused by common alleles between multiple data sets (using the same microsatellite markers) we pooled raw microsatellite scoring data. The raw microsatellite data was either accessed through publicly available databases or generously provided by the authors of the respective studies listed in Table 1. Using the data sets we calculated allelic richness as the sum of observations of the $j^{\text {th }}$ allele across the $i^{\text {th }}$ locus using GenAlEx 6.502 software [50]. Allelic richness was rarefied, using the rarefy function implemented in the Vegan package of $\mathrm{R}$ ( $\mathrm{R}$ Core Development Team, 2007), to a sample of 190 observations which allows for comparison between different sample sizes. Rarefied data was then used to calculate Shannon's diversity for the two categories as implemented in the Vegan package of R. A linear regression analysis was employed to test for differences in rarefied richness and Shannon's diversity for loci from species with resting stages versus species without. The analysis was also performed separately for diatom species only. The rationale for analysing diatoms separately was that we anticipated that the differences in ploidy (diplontic diatoms, haplontic dinoflagellates and haplo-diplontic coccolithophores), would introduce bias and obscure our results, thus we also constricted the analysis to the dominating group in the compiled data, i.e. diatoms.

\section{Exploring genetic differentiation}

In the two-population model we compared genetic differentiation under two scenarios (with and without resting stages) where two populations were connected by migration. To compare our two-population model with empirical data we collected and compiled estimates of population pairwise genetic distances (measured as $\mathrm{F}_{\mathrm{st}}$ ), and the corresponding geographic distances from published work on microalgae (Table 1). Our main interest, regarding genetic differentiation, concerned regional or local geographical scales therefore comparisons across different oceans were excluded; restricting the study geographical distances between 1 and $2500 \mathrm{~km}$. When no geographic distances were reported in the publication, we used geographical coordinates of sampling sites to measure the distances using Google earth ${ }^{\mathrm{TM}}$ (Google Inc). Using data from 13 species (listed in Table 1) $\mathrm{F}_{\mathrm{st}}$-values were plotted against geographic distances. Data points were categorized as species with the ability to form resting stages or species without resting stages. A linear regression analysis was used to describe the relation between $\mathrm{F}_{\mathrm{st}}$ and geographic distance $(\mathrm{km})$ for all collected data points. For a formal statistical test, data were made independent by first fitting a regression model to data of pairwise $F_{\mathrm{st}}$ distance for each study (16 and 6 studies, respectively with sufficient data with and without resting stages). The slopes for the two groups were then compared with a t-test for independent samples. Since slopes did not differ $(p>0.05)$ we then compared the mean $\mathrm{F}_{\mathrm{st}}$ of each study (and each species) for species with and without resting stages using a t-test for independent samples. Data $\left(\mathrm{F}_{\mathrm{st}}\right)$ were log-transformed to make variances more homogeneous.

\section{Results}

\section{The one-population model- Genetic diversity}

Based on the one-population model it was evident that when including a resting stage alleles remained in the system for a substantially longer period, compared to when resting stages were absent, meaning longer time until fixation. The number of seasons it took for one allele to become fixed was dependent on the initial population size (number of alleles sampled), this was true both with and without resting stages (Fig. S1). The number of unique alleles in the starting distribution did however not affect the time to reach fixation (Fig. S2). Both life-history strategies experienced a drastic drop in number of unique alleles already after the first season (Fig. 2). The population without resting stages reached complete fixation for one allele early during the 
Table 1 Data on species, number of loci, number of $\mathrm{F}_{\mathrm{st}^{-}}$ values included in the analysis and information on resting stage formation collected in the systematic literature review

\begin{tabular}{|c|c|c|c|c|}
\hline Species & No. of loci & $\mathrm{F}_{\mathrm{ST}}$ & Resting stage & Reference \\
\hline Alexandrium catenella & 12 & 5 & yes & Masseret et al. [65] \\
\hline Alexandrium fundyense & 4 & 27 & yes & Richlen et al. [66]* \\
\hline Alexandrium fundyense & 5 & 15 & yes & Erdner et al. [67]* \\
\hline Alexandrium ostenfeldii & 9 & - & yes & Nagai et al. [68]* \\
\hline Alexandrium pacificum & 8 & 55 & yes & Genovesi et al. [69] \\
\hline Alexandrium minutum & 7 & 15 & yes & Casabianca et al. [17]* \\
\hline Alexandrium minutum & 12 & 30 & yes & Dia et al. [21]* \\
\hline Alexandrium tamarense & 18 & - & yes & Alpermann et al. $[70,71]^{*}$ \\
\hline Astrionella formosa & 9 & - & no & Van den Wyngeart et al. [72]* \\
\hline Cochlodinium polykrikoides & 10 & 78 & yes & Nagai et al. [73] \\
\hline Ditylum brightwellii & 3 & 11 & yes & Rynearson and Ambrust $[74,75]^{*}$ \\
\hline Ditylum brightwellii & 3 & 57 & yes & Rynearson et al. [13] \\
\hline Ditylum brightwellii & 2 & 4 & yes & Rynearson et al. [76]* \\
\hline Emiliania huxleyi & 10 & 36 & no & Cook et al. [77]* \\
\hline Emiliania huxleyi & 5 & - & no & Kreuger-Hadfield et al. [78]* \\
\hline Eunotia bilunaris & 6 & 27 & yes & Vanormelingen et al. [14]* \\
\hline Karenia brevis & 5 & 9 & no & Henrichs et al. [79] \\
\hline Oxyrrhis marina & 9 & 15 & no & Lowe et al. [80] \\
\hline Pseudo-nitzschia pungens & 4 & - & no & Adams et al. [81]* \\
\hline Pseudo-nitzschia pungens & 6 & 45 & no & Casteleyn et al. [82]* \\
\hline Pseudo-nitzschia pungens & 6 & 3 & no & Casteleyn et al. [83] \\
\hline Pseudo-nitzschia pungens & 6 & 1 & no & Evans et al. [15] \\
\hline Pseudo-nitzschia multistriata & 7 & - & no & Tesson et al. $[84,85]^{*}$ \\
\hline Sellaphora capitata & 7 & 18 & yes & Vanormelingen et al. [14]* \\
\hline Sellaphora capitata & 10 & 3 & yes & Evans et al. [86] \\
\hline Skeletonema marinoi & 8 & 27 & yes & Godhe and Härnström [52] \\
\hline Skeletonema marinoi & 8 & 21 & yes & Godhe et al. [11] \\
\hline Skeletonema marinoi & 8 & 45 & yes & Sjöqvist et al. [19]* \\
\hline Skeletonema marinoi & 8 & - & yes & Godhe et al. [87] \\
\hline
\end{tabular}

Raw microsatellite data from the references marked with $(*)$ are included in the diversity analysis. simulation. However, the decrease in number of alleles was slowed down in the presence of a seed-bank. As a consequence populations with resting stages exhibited a higher number of alleles and thereby genetic diversity over a longer time period compared to populations without resting stages. Although the population with a resting stage also exhibited a drastic reduction in number alleles as a result of genetic drift, the population did not reach complete fixation for the duration of the simulated run. When the proportion of re-seeding from the sediment increased the time to fixation increased (Fig. 3). The impact of resting stages was not only determined by the proportion of alleles that came from the sediment, it also depended on the lifespan of the dormant stage and from how deep down resting stages in the sediment could be resuspended. Figure 4 shows that when successively deeper layers of the seed bank contributed to the next active population the time to fixation got longer.

\section{The two-population model- Genetic differentiation}

When we included migration into the model and measured genetic differentiation between two populations we could also see a strong effect from resting stages. Initially the two population were genetically different, that is they shared no alleles. Over time, during the simulation the two populations gradually homogenized as alleles were exchanged through migration, and thereby a decrease in genetic differentiation. When the re-seeding from the sediment to the water column was low (5\%), populations only exhibited a marginally higher degree of genetic differentiation (Fig. 5a, $\mathrm{d}$ and $\mathrm{g}$ ). When the water column-sediment link was strengthened ( $\geq 25 \%$ re-seeding from the sediment) the populations remained differentiated for a longer period of time (Fig. 5b,c,e,f,h and i). The difference between the two life history strategies was larger at low migration rates, but even with a migration rate as high as $20 \%$ a medium link 


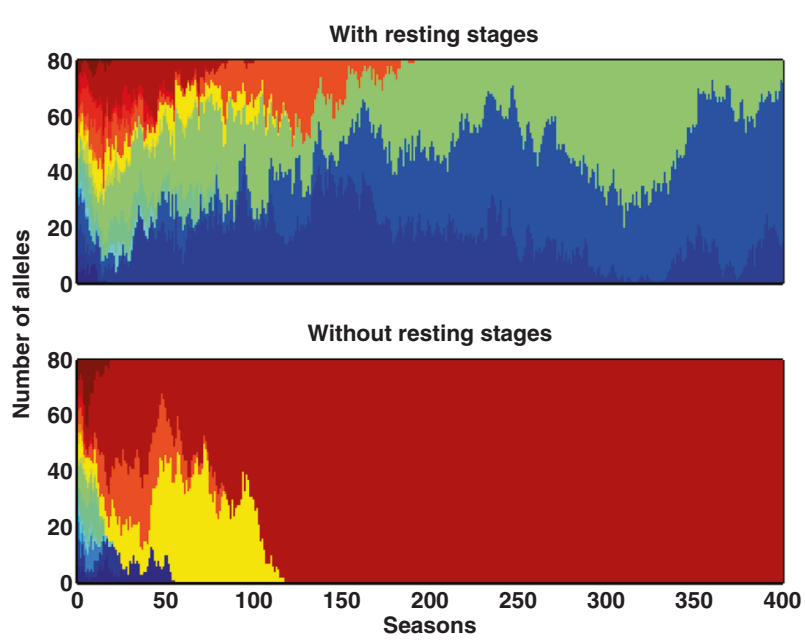

Fig. 2 A realisation of the one population model illustrating the combination of different alleles over time for the two different life history strategies. The simulations were run with 80 alleles starting from a distribution with 20 unique alleles (represented by different colours). The number of unique alleles dropped quickly during the first seasons, therefore all 20 different colours are not seen when the result is plotted on a long time scale. For populations with resting stages each season was started by $25 \%$ of alleles being re-seeded from the sediment and resting stages having a lifespan of 20 seasons

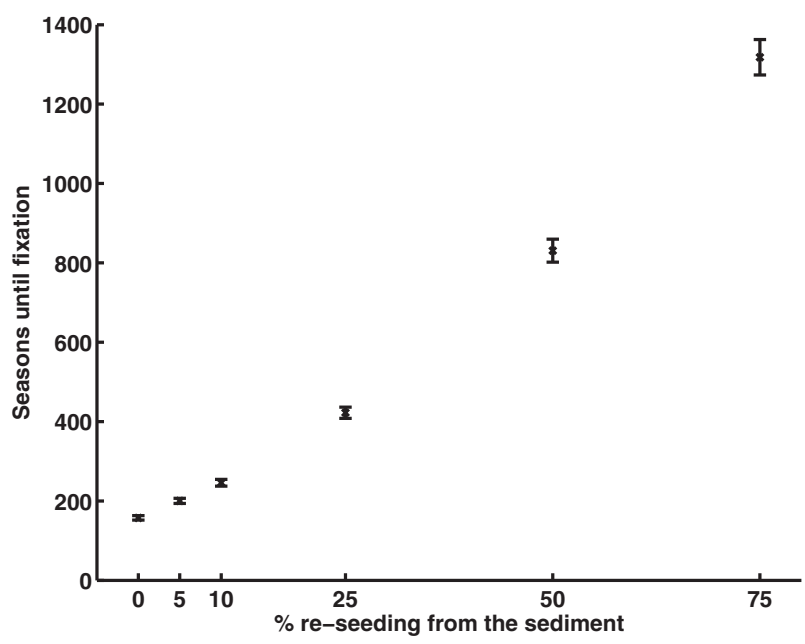

Fig. 3 Effect on the time to fixation by increased proportion of alleles from the sediment that re-seeded the next season's population (mean \pm 95\% confidence interval from 1000 simulations). The simulation was run with 80 alleles starting from a set with 20 unique alleles. Resting stages had a lifespan of 20 seasons

(25\% re-seeding from the sediment) between the sediment and the water column showed greater differentiation for populations with resting stages (Fig. 5h). When the starting size was increased from 80 alleles (Fig. 5) to 2000 alleles the homogenizing effect of the migration was higher, and the populations (both with and without resting stages) reached zero genetic differentiation faster (Fig. S3). Increasing the start size over 2000 however did not affect the results further (data not shown).

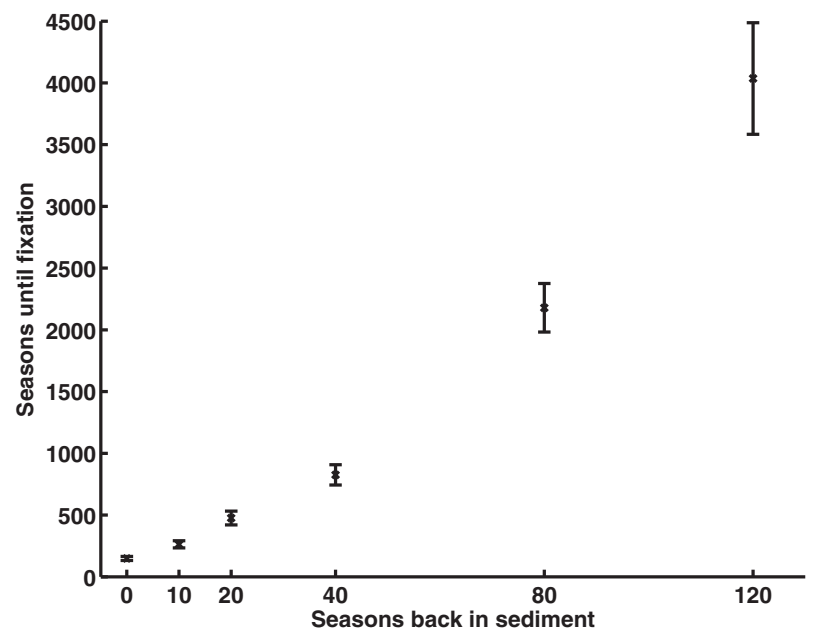

Fig. 4 Effect of increased number of historic seasons from which alleles in the sediment could re-seed the next population. The results show number of seasons until fixation (mean $\pm 95 \%$ confidence interval from 1000 simulations). The simulations were run with 80 alleles starting from a distribution with 20 unique alleles and $25 \%$ of a new bloom was started from the sediment

\section{Systematic literature review}

\section{Genetic diversity}

Collection of empirical data resulted in a total of 95 microsatellite loci belonging to 12 microalgal species gathered from 21 different studies (detailed in Table 1). Assessment of adequate rarefaction depth led to the exclusion of 33 loci, leaving 62 loci belonging to 9 species. Out of the 33 loci omitted from the analysis 32 belonged to the dinoflagellate genus Alexandrium, which are haploid in the vegetative state, and 1 locus belonging to the coccolithophore Emiliania huxleyi. When all data, from the 62 loci, were pooled we observed a slightly higher average in rarefied allelic richness and Shannon diversity in loci of species with a resting stage (Fig. S4a-b), although this difference was not statistically significant $(p=0.2$ and 0.07 , respectively). However, when we focused only on diatoms statistical analysis revealed a significantly higher rarefied allelic richness $(p=0.001)$ and Shannon diversity $(p=$ 0.006) at loci in species with a resting stage (Fig. 6a,b). This result was based on a total of 40 microsatellite loci belonging to 7 different species (4 species without a resting stage and 3 with a resting stage).

\section{Genetic differentiation}

Genetic $\left(\mathrm{F}_{\mathrm{st}}\right)$ and geographic data, collected from the literature, were first examined with a regression analysis on independent data, which showed no overall support for a significant isolation by distance (Fig. 7), using either 


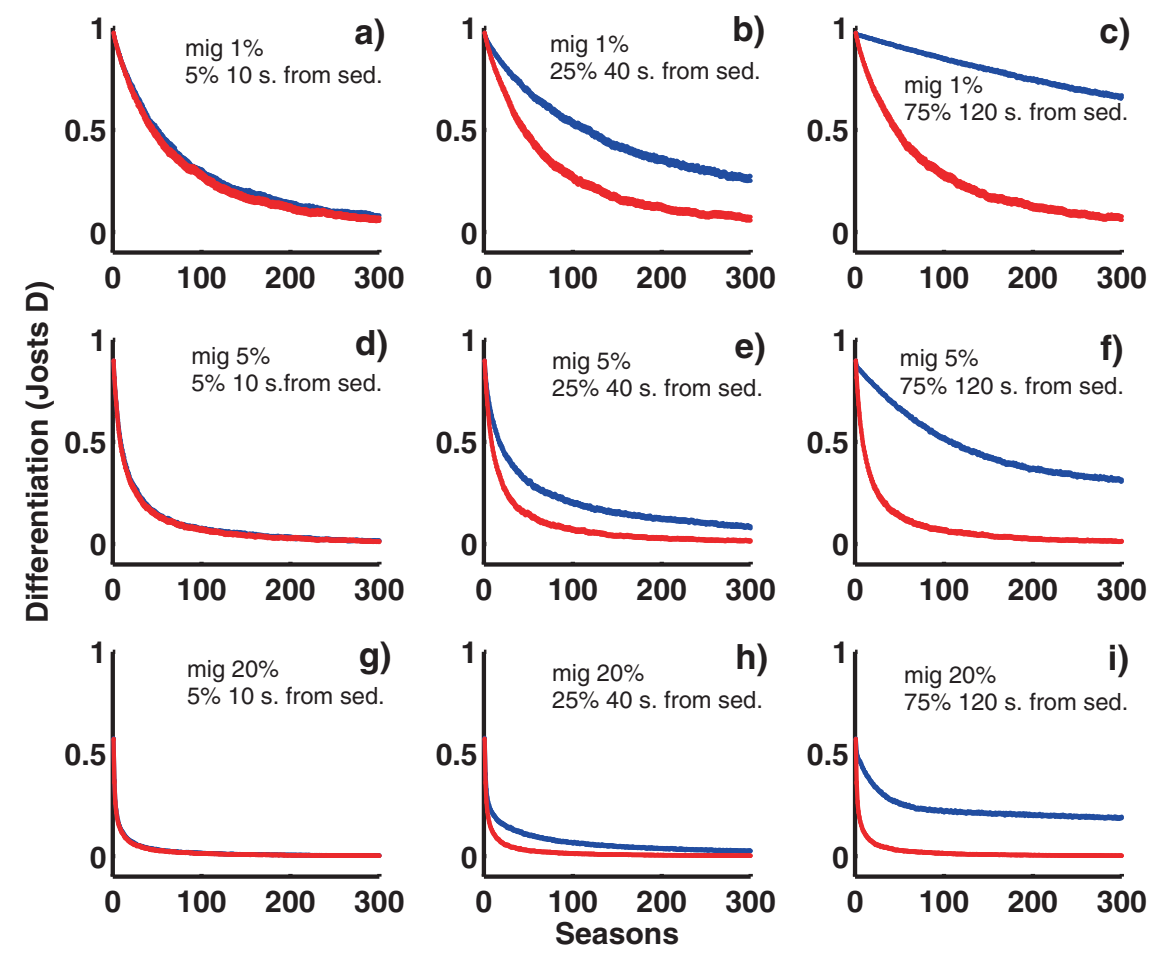

Fig. 5 Changes in genetic differentiation (Jost's D) over time between two populations linked by migration. Blue lines show results for populations with a life history strategy including resting stages while red lines show results for populations that does not include resting stages. Solid lines show the mean calculated from 1000 simulations and the $95 \%$ confidence intervals is only visible as thickening of the solid line. All simulations were run with 80 alleles in each population

untransformed or logarithmically transformed distance data $(p>0.05)$. However, species with resting stages showed a significantly higher $\mathrm{F}_{\mathrm{st}}$ than species without resting stages ( $p=0.0013$, t-test). This difference could not be explained by a difference in the mean pairwise distance between samples for species with and without resting stages $(p>$ 0.05 , t-test). These results corroborate the results from the model.

\section{Discussion}

Here we present a conceptual framework that strongly emphasizes the role of resting stages on the microevolutionary processes in microalgae. Using population-based simulations we were able to show that resting stages can serve as a genetic reservoir that counteracts the effect of genetic drift and migration, thus giving rise to higher genetic diversity and population genetic differentiation. This is in comparison to species that do not form resting stages. Based on the one-population model it was evident that the stronger the link between the active population and the seed bank, the longer it took to reach fixation for a starting from different sets with 20 unique alleles. Figure a-c was simulated with $1 \%$ migration, d-f with $5 \%$ migration and g-i with $20 \%$ migration. Figure a, d, g was simulated with a low connection to the sediment (5\% reseeding from 10 seasons back). Figure b,e,h was simulated with a medium sediment connection $(25 \%$ reseeding from 40 seasons back) and figure $\mathbf{c}, \mathbf{f}, \mathbf{i}$ was simulated with a high sediment connection ( $75 \%$ reseeding from 120 seasons back)

particular allele. Similarly, when we incorporated migration into the model and simulated population genetic differentiation, populations remained differentiated for a longer period of time if they had a life-history strategy that included a resting stage. This was true even when migration between the two active populations was as high as $20 \%$. Our results signify that the presence of a local seed bank can have a significant influence on microevolutionary processes. The active population in the water column is connected to historic populations through re-seeding of resting stages that anchor the population. In natural populations there are of course other factors that may either enhance or attenuate these effects, factors that we have neglected in our model. Here we have made assumptions such that there are no fitness differences, no mutations and no density dependence, leaving genetic drift as the driving evolutionary force, which is a strongly simplified scheme. Nevertheless, when we collected and compiled empirical data from the literature we found similar patterns as those suggested by our models.

Increased genetic diversity in populations with resting stages has previously been recorded for plant and zooplankton species $[28,32,51]$. Also with our one-population 


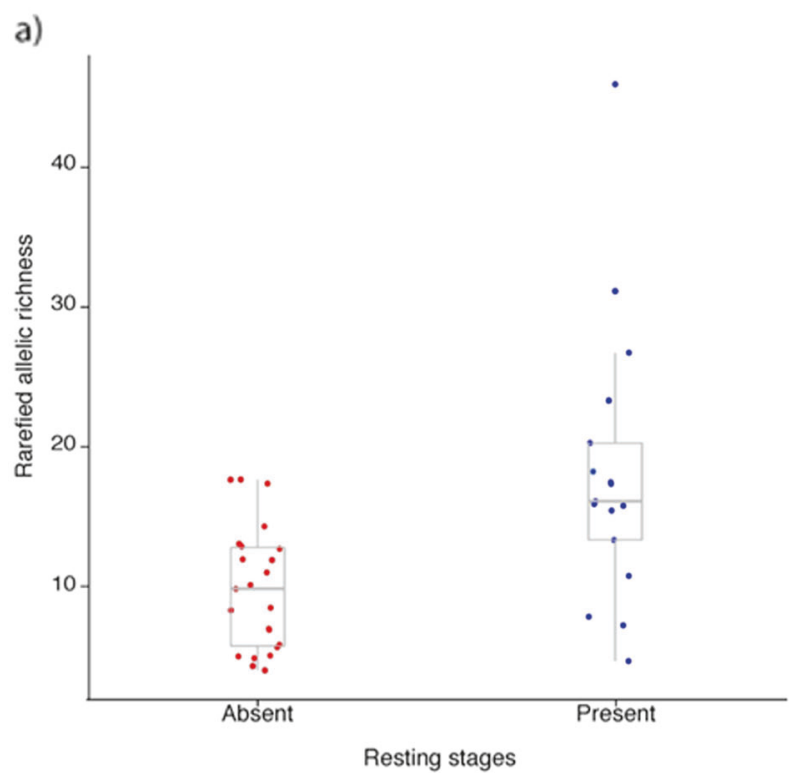

Fig. 6 a,b. Summary of literature based genetic diversity for microsatellite loci $(n=40)$ in diatom species with resting stages present $(n=3)$ versus absent $(n=4)$ in the life-history. Genetic diversity is

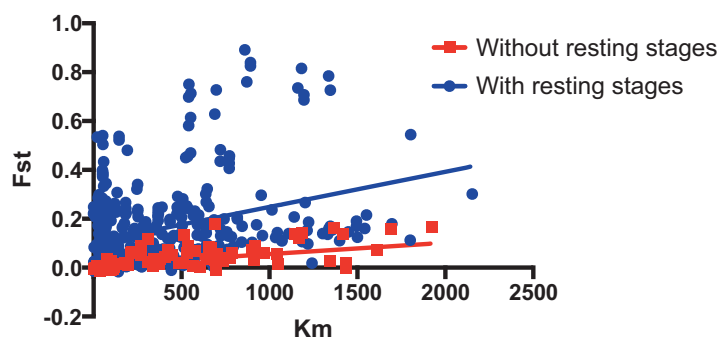

Fig. 7 Genetic differentiation $\left(\mathrm{F}_{\mathrm{st}}\right)$ plotted against geographic distance $(\mathrm{km})$ for species with a life history strategy including (blue) and not including resting stages (red), using published $\mathrm{F}_{\mathrm{st}}$ values (see Table 1). The trend lines are included for illustrative purpose

model we could show that when genetic drift is the only evolutionary force present, resting stage formation resulted in a higher genetic diversity (i.e. allelic richness) compared to life-history strategies that do not form resting stages. When we compared these results with empirically based estimates of allelic richness (rarefied richness and Shannon diversity) and limited the analysis to include diatom species we found statistical support for a higher allelic richness in species with the ability to form resting stages. However, when we included all the gathered data a higher diversity in species with a resting stage was poorly supported. One potential reason for this is that the data included a diverse collection of species that differ in their (amongst other characteristics) ploidy and life cycles. In the planktonic state dinoflagellates are haploid and thus only have the possibility of half the number of alleles per locus compared to a diploid diatom and coccolithophores. Coccolithophores do however alternate between a haploid and diploid phase and

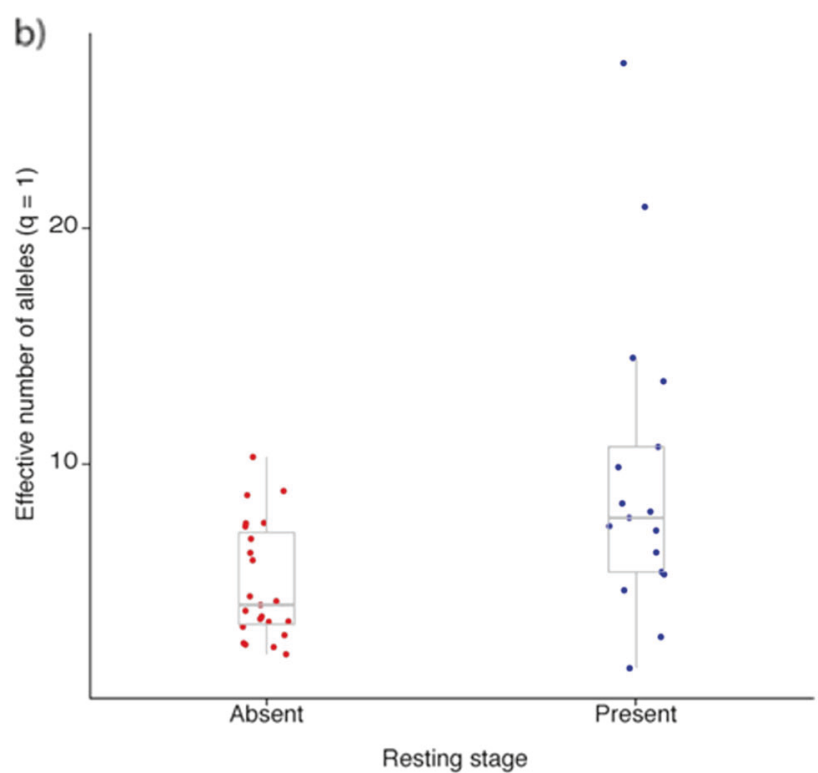

expressed as a) allelic richness rarefied to a sample size of 190 observations $(\mathrm{F}=12.65, p=0.001), \mathbf{b})$ the exponential of Shannon Index, $\mathrm{e}^{\mathrm{H}},(\mathrm{F}=8.26, p=0.006)$

it should be mentioned that the data collected from the literature only included diploid genotypes.

In microalgae little is known about the genetic link between resting stages and the active populations. To date only one such study has been conducted which showed that the dormant population was also representative of the planktonic populations, i.e. genetic diversity and nonsignificant $\mathrm{F}_{\mathrm{st}}$ [52]. The importance of resting stages in providing an inoculum for bloom initiation has been shown several times [53-56] and that their abundance may be used to forecast next season's bloom [53]. However, the proportion of individuals inoculated from last year's bloom versus the proportion from the deeper sediment layers is unknown and likely to differ between habitats and species. The time resting stages remain viable vary between species [57] and is also affected by anoxic conditions in the sediment $[57,58]$. The presence and distribution of bioturbators will also affect both the burial and the disinterment of resting stages in the sediment and can thus affect the number of cysts that are able to re-seed [59]. We tested the model for a wide range of proportions of re-seeded alleles and life spans of resting stages to compensate for the variability of these parameters and found significant effects of resting stages in all tested scenarios.

When examining genetic differentiation our literature review, in agreement with the model, showed higher genetic differentiation for the species forming resting stages compared to the species not forming resting stages. Since the number of studies providing information on genetic differentiation in microalgae is limited we chose to include all information available. This makes the dataset to some 
degree skewed. For example, some species have been studied more intensively than others and there is also a higher number of data points from species that form resting stages (16 studies including 9 species) than from species that do not form resting stages (6 studies including 4 species). In some of the species included in the analysis it is uncertain if resting stages are formed or not. K. brevis, O. marina and $P$. pungens fall within this category. They have for the purpose of this analysis been categorized as not forming resting stages with the motivation that even if cysts do exist in these species it is unlikely that they are long-lived and build up seed banks contributing extensively to the genetic structure of active populations in the water column.

When looking specifically at the effect of resting stages on the genetic differentiation between populations, studies on higher plant species indicate that seed banks weaken genetic differentiation between populations [30,31]. However, many factors differ between the plants and the microalgal systems we consider here, the most notable is probably the enormous population sizes found in microalgae. Planktonic microalgae are in several aspects more similar to zooplankton than to many plants, they share the characteristics of high dispersal potential, large population sizes and rapid growth rates. In zooplankton, as in microalgae, large genetic differentiation at short geographical distances despite potentially high gene flow has been found [60]. The high degree of structure in these systems has been explained by founder effects, priority effects and local adaptation $[60,61]$. In the monopolization hypothesis the paradox of genetic structure under dispersal and gene flow is explained by combining founder events and rapid local adaptation together with a buffering (anchoring) effect from a seed bank [38]. Here we show that seed banks alone with no fitness differences (no adaptation) included can maintain high genetic differentiation despite high levels of gene flow, indicating that resting stages may play a bigger role in the structuring of populations than previously considered. In microalgal systems an anchoring/buffering effect of resting stages has also been discussed [52,57,58]. The effect of accumulation of long-term resting stages on the genetic differentiation between populations has, however, to our knowledge never been studied in depth in planktonic species before.

The total effect of resting stages on the genetic diversity and structure of populations is likely more complex than what is considered in our model. Our model has focused on the effect dormant stages without natural selection and thus no adaptive evolution. Dormant stages will certainly increase the standing genetic variation and consequently the potential for local adaptation. Their influence on the rate of adaptive evolution will nevertheless depend on whether selection is directional or fluctuating [36]. The anchoring effect allows for local adaptation over time, as it is dependent on the standing genetic variation in a population [62]. However, the refuge that dormancy facilitates during unfavourable conditions [25,63], will weaken the effect of natural selection [27], compared to life-cycles with no resting stages. The genetic diversity archived in the sediment is ultimately an important resource for populations to cope with local environmental change. This was shown in the dinoflagellate Alexandrium ostenfeldii where some genotypes, established from cysts in the sediment, thrived in present day conditions and others in future predicted temperatures and salinities [58]. Such reports indeed indicate that genetically diverse seed banks can store high phenotypic diversity. Studies focusing on the genetics of seed banks can also assist in forecasting adaptation potential to future environmental changes as historic evolutionary changes can be followed over time [64]. More research looking beyond what is to be found in the water column is needed to fully understand the genetic structure and the adaptive potential of microalgal species with the ability to form resting stages.

Acknowledgements We want to thank all the authors of the papers which data was used in our diversity analysis. Raw microsatellite data from these papers were kindly provided by Deana Erdner, Mindy Richlen, Anke Kremp, Silvia Casabianca, Aliou Dia, Tilman Alpermann, Silke Van den Wyngeart, Tatiana Rynearson, Stacy KruegerHadfield, Nicolaus Adams, Griet Castelyn, Sylvie Tesson, Gustaaf Hallegraeff and Suellen Cook. We also want to thank Fabian Roger for valuable help with the diversity analysis. LS and PRJ were funded through the Linnaeus Centre for Marine Evolutionary Biology at the University of Gothenburg (www.cemeb.science.gu.se/) and the Swedish Research Council. AG and JS were funded through Swedish Research Council Formas (219-2012-2070).

\section{Compliance with ethical standards}

Conflict of interest The authors declare that they have no conflict of interest.

\section{References}

1. Orsini L, Vanoverbeke J, Swillen I, Mergeay J, Meester L. Drivers of population genetic differentiation in the wild: isolation by dispersal limitation, isolation by adaptation and isolation by colonization. Mol Ecol. 2013;22:5983-99.

2. Hartl DL, Clark AG. Principles of Population Genetics 4th edn., (2007) Sinauer Associates, Sunderland, MA, xiii-652.

3. Manel S, Schwartz MK, Luikart G, Taberlet P. Landscape genetics: combining landscape ecology and population genetics. Trends in ecology \& evolution. 2003;18:189-97.

4. Waples RS, Gaggiotti O. INVITED REVIEW: What is a population? An empirical evaluation of some genetic methods for identifying the number of gene pools and their degree of connectivity. Mol Ecol. 2006;15:1419-39.

5. Wright S. Isolation by distance. Genetics. 1943;28:114-38.

6. Fenchel T, Finlay BJ. The ubiquity of small species: patterns of local and global diversity. AIBS Bulletin. 2004;54:777-84.

7. Finlay BJ. Global dispersal of free-living microbial eukaryote species. Science. 2002;296:1061-3. 
8. Foissner W, Chao A, Katz LA. Diversity and geographic distribution of ciliates (Protista: Ciliophora). Biodiversity and Conservation. 2008;17:345-63.

9. Medlin LK. If everything is everywhere, do they share a common gene pool? Gene. 2007;406:180-3.

10. Whitfield J. Biogeography: is everything everywhere? Science. 2005;310:960.

11. Godhe A, Egardt J, Kleinhans D, Sundqvist L, Hordoir R, Jonsson PR. Seascape analysis reveals regional gene flow patterns among populations of a marine planktonic diatom. Proc R Soc Lond B: Biol Sci. 2013;280:20131599.

12. Lebret K, Kritzberg ES, Figueroa R, Rengefors K. Genetic diversity within and genetic differentiation between blooms of a microalgal species. Environ Microbiol. 2012;14:2395-404.

13. Rynearson T, Newton J, Armbrust E. Spring bloom development, genetic variation, and population succession in the planktonic diatom Ditylum brightwellii. Limnol Oceanogr. 2006;51: 1249-61.

14. Vanormelingen P, Evans KM, Mann DG, Lance S, Debeer AE, D'hondt S, et al. Genotypic diversity and differentiation among populations of two benthic freshwater diatoms as revealed by microsatellites. Mol Ecol. 2015;24:4433-48.

15. Evans KM, Kühn SF, Hayes PK. High levels of genetic diversity and low levels of genetic differentiation in North Sea Pseudonitzschia pungens (Bacillariophyceae) populations. J Phycol. 2005;41:506-14.

16. Sournia A. Form and function in marine phytoplankton. Biological Reviews. 1982;57:347-94.

17. Casabianca S, Penna A, Pecchioli E, Jordi A, Basterretxea G, Vernesi C Population genetic structure and connectivity of the harmful dinoflagellate Alexandrium minutum in the Mediterranean Sea. Proceedings Biological sciences. 2012;279(1726): 129-38.

18. Rengefors K, Logares R, Laybourn-Parry J, Gast RJ. Evidence of concurrent local adaptation and high phenotypic plasticity in a polar microeukaryote. Environ Microbiol. 2015;17:1510-9.

19. Sjöqvist C, Godhe A, Jonsson P, Sundqvist L, Kremp A. Local adaptation and oceanographic connectivity patterns explain genetic differentiation of a marine diatom across the North Sea-Baltic Sea salinity gradient. Mol Ecol. 2015;24:2871-85.

20. Sassenhagen I, Sefbom J, Säll T, Godhe A, Rengefors K. Freshwater protists do not go with the flow: Population structure in Gonyostomum semen independent of connectivity among lakes. Environ Microbiol. 2015;17:5063-72.

21. Dia A, Guillou L, Mauger S, Bigeard E, Marie D, Valero M, et al. Spatiotemporal changes in the genetic diversity of harmful algal blooms caused by the toxic dinoflagellate Alexandrium minutum. Mol Ecol. 2014;23:549-60.

22. Härnström K, Ellegaard M, Andersen TJ, Godhe A Hundred years of genetic structure in a sediment revived diatom population. Proceedings of the National Academy of Sciences. 2011;108 (10):4252-7.

23. Von Dassow P, Montresor M. Unveiling the mysteries of phytoplankton life cycles: patterns and opportunities behind complexity. J Plankton Res. 2010;33:3-12.

24. Binder BJ, Anderson DM. Biochemical composition and metabolic activity of Scrippsiella trochoidea (Dinophyceae) resting cysts. J Phycol. 1990;26:289-98.

25. Hensen V. Über die Bestimmung des Planktons oder des im Meere treibenden Materials an Pflanzen und Tieren. Schmidt \& Klaunig;1887. Kiel, Germany.

26. Ribeiro S, Berge $\mathrm{T}$, Lundholm $\mathrm{N}$, Andersen TJ, Abrantes $\mathrm{F}$, Ellegaard M. Phytoplankton growth after a century of dormancy illuminates past resilience to catastrophic darkness. Nat Commun. $2011 ; 2: 311$
27. Lennon JT, Jones SE. Microbial seed banks: the ecological and evolutionary implications of dormancy. Nat Rev Microbiol. 2011;9:119.

28. Brendonck L, De Meester L. Egg banks in freshwater zooplankton: evolutionary and ecological archives in the sediment. Hydrobiologia. 2003;491:65-84.

29. Andrewartha H. Diapause in relation to the ecology of insects. Biological Reviews. 1952;27:50-107.

30. Vitalis R, Glémin S, Olivieri I. When genes go to sleep: the population genetic consequences of seed dormancy and monocarpic perenniality. Am Nat. 2004;163:295-311.

31. Honnay O, Bossuyt B, Jacquemyn H, Shimono A, Uchiyama K. Can a seed bank maintain the genetic variation in the above ground plant population? Oikos. 2008;117:1-5.

32. McCue K, Holtsford T. Seed bank influences on genetic diversity in the rare annual Clarkia springvillensis (Onagraceae). Am J Bot. 1998;85:30.

33. Templeton AR, Levin DA. Evolutionary consequences of seed pools. Am Nat. 1979;114:232-49.

34. Hedrick PW. Genetic polymorphism in a temporally varying environment: effects of delayed germination or diapause. Heredity. 1995;75:164.

35. Chesson PL. The storage effect in stochastic population models. In: Levin S.A., Hallam T.G. (eds) Mathematical Ecology. Lecture Notes in Biomathematics, vol 54. Springer, Berlin, Heidelberg, 1984;54:76-89.

36. Hairston NG Jr, De Stasio BT Jr. Rate of evolution slowed by a dormant propagule pool. Nature. 1988;336:239.

37. Boileau MG, Hebert PD, Schwartz SS. Non-equilibrium gene frequency divergence: persistent founder effects in natural populations. J Evol Biol. 1992;5:25-39.

38. De Meester L, Gómez A, Okamura B, Schwenk K. The Monopolization Hypothesis and the dispersal-gene flow paradox in aquatic organisms. Acta oecologica. 2002;23:121-35.

39. Rengefors K, Kremp A, Reusch TB, Wood AM. Genetic diversity and evolution in eukaryotic phytoplankton: revelations from population genetic studies. J Plankton Res. 2017;39:165-79.

40. McQuoid MR, Hobson LA. Diatom resting stages. J Phycol. 1996;32:889-902.

41. Jost L. GST and its relatives do not measure differentiation. Mol Ecol. 2008;17:4015-26.

42. Vieira MLC, Santini L, Diniz AL, Munhoz CdF. Microsatellite markers: what they mean and why they are so useful. Genet Mol Biol. 2016;39:312-28.

43. Walker LM. Evidence for a sexual cycle in the Florida red tide dinoflagellate, Ptychodiscus brevis (=Gymnodinium breve). Transactions of the American Microscopical Society. 1982;101:287-93.

44. Persson A, Smith BC, Morton S, Shuler A, Wikfors GH. Sexual life stages and temperature dependent morphological changes allow cryptic occurrence of the Florida red tide dinoflagellate Karenia brevis. Harmful Algae. 2013;30:1-9.

45. Goodman, D.K. Dinoflagellate cysts in ancient and modern sediments in The Biology of Dinoflagellates, Botanical Monographs (ed. Taylor F.JR) 649-722 (Blackwell, 1987) Oxford.

46. Montagnes DJ, Lowe CD, Martin L, Watts PC, Downes-Tettmar $\mathrm{N}$, Yang Z, et al. Oxyrrhis marina growth, sex and reproduction. J Plankton Res. 2010;33:615-27.

47. McQuoid MR, Godhe A. Recruitment of coastal planktonic diatoms from benthic versus pelagic cells: Variations in bloom development and species composition. Limnol Oceanogr. 2004:49:1123-33.

48. Montresor M, Di Prisco C, Sarno D, Margiotta F, Zingone A. Diversity and germination patterns of diatom resting stages at a coastal Mediterranean site. Mar Ecol Prog Ser. 2013;484:79-95. 
49. Orlova TY, Morozova T. Resting stages of microalgae in recent marine sediments of Peter the Great Bay, Sea of Japan. Russian journal of marine biology. 2009;35:313-22.

50. Peakall R, Smouse PE. GENALEX 6: genetic analysis in Excel. Population genetic software for teaching and research. Molecular Ecology Resources. 2006;6:288-95.

51. Hairston NG. Zooplankton egg banks as biotic reservoirs in changing environments. Limnol Oceanogr. 1996;41:1087-92.

52. Godhe A, Härnström K. Linking the planktonic and benthic habitat: genetic structure of the marine diatom Skeletonema marinoi. Mol Ecol. 2010;19:4478-90.

53. Anderson DM, Keafer BA, Kleindinst JL, McGillicuddy DJ Jr, Martin JL, Norton K, et al. Alexandrium fundyense cysts in the Gulf of Maine: long-term time series of abundance and distribution, and linkages to past and future blooms. Deep Sea Research Part II: Topical Studies in Oceanography. 2014; 103:6-26.

54. Anderson D, Chisholm S, Watras C. Importance of life cycle events in the population dynamics of Gonyaulax tamarensis. Marine Biology. 1983;76:179-89.

55. Heaney S, Chapman D, Morison $\mathrm{H}$. The role of the cyst stage in the seasonal growth of the dinoflagellate Ceratium hirundinella within a small productive lake. British Phycological. Journal. 1983;18:47-59.

56. Rengefors K. Seasonal succession of dinoflagellates coupled to the benthic cyst dynamics in Lake Erken. Ergebnisse der Limnologie. 1998;51:123-41.

57. Lundholm N, Ribeiro S, Andersen TJ, Koch T, Godhe A, Ekelund F, et al. Buried alive-germination of up to a century-old marine protist resting stages. Phycologia. 2011;50:629-40.

58. Kremp A, Oja J, LeTortorec AH, Hakanen P, Tahvanainen P, Tuimala J, et al. Diverse seed banks favour adaptation of microalgal populations to future climate conditions. Environ Microbiol. 2016;18:679-91.

59. Shull DH, Kremp A, Mayer LM. Bioturbation, germination and deposition of Alexandrium fundyense cysts in the Gulf of Maine. Deep Sea Research Part II: Topical Studies in Oceanography. 2014;103:66-78.

60. De Meester L. Local genetic differentiation and adaptation in freshwater zooplankton populations: patterns and processes. Ecoscience. 1996;3:385-99.

61. Gómez A, Adcock G, Lunt D, Carvalho G. The interplay between colonization history and gene flow in passively dispersing zooplankton: microsatellite analysis of rotifer resting egg banks. J Evol Biol. 2002;15:158-71.

62. Hoffmann AA, Sgrò CM. Climate change and evolutionary adaptation. Nature. 2011;470:479.

63. Anderson DM. Cysts as factors in Pyrodinium bahamense ecology. In: Biology, epidemiology and management of Pyrodinium red tides ICLARM Conference Proceedings (ed. Hallegraeff GM, Maclean JL), Fisheries Department, Manila, Philippines. 1989;81-89.

64. Orsini L, Schwenk K, De Meester L, Colbourne JK, Pfrender ME, Weider LJ. The evolutionary time machine: forecasting how populations can adapt to changing environments using dormant propagules. Trends in ecology \& evolution. 2013;28:274.

65. Masseret E, Grzebyk D, Nagai S, Genovesi B, Lasserre B, Laabir M, Collos Y, Vaquer A, Berrebi P. Unexpected genetic diversity among and within populations of the toxic dinoflagellate Alexandrium catenella as revealed by nuclear microsatellite markers. Appl Environ Microbiol. 2009;75:2037-45.

66. Richlen ML, Erdner DL, McCauley LA, Libera K, Anderson DM. Extensive genetic diversity and rapid population differentiation during blooms of Alexandrium fundyense (Dinophyceae) in an isolated salt pond on Cape Cod, MA, USA. Ecol Evol. 2012;2:2588-99.
67. Erdner DL, Richlen M, McCauley LA, Anderson DM. Diversity and dynamics of a widespread bloom of the toxic dinoflagellate Alexandrium fundyense. PLoS One. 2011;6:e22965.

68. Nagai S, Yasuike M, Nakamura Y, Tahvanainen P, Kremp A. Development of ten microsatellite markers for Alexandrium ostenfeldii, a bloom-forming dinoflagellate producing diverse phycotoxins. J Appl Phy. 2015;27:2333-9.

69. Genovesi B, Berrebi P, Nagai S, Reynaud N, Wang J, Masseret E. Geographic structure evidenced in the toxic dinoflagellate Alexandrium pacificum Litaker (A. catenella-group IV (Whedon \& Kofoid) Balech) along Japanese and Chinese coastal waters. Mar Pollut Bull. 2015;98:95-105.

70. Alpermann TJ, Beszteri B, John U, Tillmann U, Cembella AD. Implications of life-history transitions on the population genetic structure of the toxigenic marine dinoflagellate Alexandrium tamarense. Mol Ecol. 2009;18:2122-33.

71. Alpermann TJ, Tillmann U, Beszteri B, Cembella AD, John U. Phenotypic variation and genotypic diversity in a planktonic population of the toxigenic marine dinoflagellate Alexandrium tamarense (Dinophyceae). J Phy. 2010;46:18-32.

72. Van den Wyngaert S, Möst M, Freimann R, Ibelings BW, Spaak P. Hidden diversity in the freshwater planktonic diatom Asterionella formosa. Mol Ecol. 2015;24:2955-72.

73. Nagai S, Nishitani G, Sakamoto S, Sugaya T, Lee C, Kim C, Itakura S, Yamaguchi M. Genetic structuring and transfer of marine dinoflagellate Cochlodinium polykrikoides in Japanese and Korean coastal waters revealed by microsatellites. Mol Ecol. 2009;18:2337-52.

74. Rynearson TA, Virginia Armbrust E. Genetic differentiation among populations of the planktonic marine diatom Ditylum brightwellii (Bacillariophyceae). J Phycol. 2004;40:34-43.

75. Rynearson TA, Armbrust E. Maintenance of clonal diversity during a spring bloom of the centric diatom Ditylum brightwellii. Mol Ecol. 2005;14:1631-40.

76. Rynearson TA, Lin EO, Armbrust EV. Metapopulation structure in the planktonic diatom Ditylum brightwellii (Bacillariophyceae). Protist. 2009;160:111-21.

77. Cook SS, Jones RC, Vaillancourt RE, Hallegraeff GM. Genetic differentiation among Australian and Southern Ocean populations of the ubiquitous coccolithophore Emiliania huxleyi (Haptophyta). Phycologia. 2013;52:368-74.

78. Krueger-Hadfield SA, Balestreri C, Schroeder J, Highfield A, Helaouët P, Allum J, Moate R, Lohbeck KT, Miller P \& Riebesell U (2014) Genotyping an Emiliania huxleyi (Prymnesiophyceae) bloom event in the North Sea reveals evidence of asexual reproduction. Biogeosciences 5215.

79. Henrichs DW, Renshaw MA, Gold JR, Campbell L. Populationgenetic structure of the toxic dinoflagellate Karenia brevis from the Gulf of Mexico. J Plankton Res. 2013;35:427-32.

80. Lowe CD, Montagnes DJ, Martin LE, Watts PC. High genetic diversity and fine-scale spatial structure in the marine flagellate Oxyrrhis marina (Dinophyceae) uncovered by microsatellite loci. PLoS One. 2010;5:e15557.

81. Adams N, Trainer V, Rocap G, Herwig R, Hauser L. Genetic population structure of Pseudo-nitzschia pungens (Bacillariophyceae) from the Pacific Northwest and the North Sea. J Phycol. 2009;45:1037-45.

82. Casteleyn G, Evans KM, Backeljau T, D'hondt S, Chepurnov VA, Sabbe K, Vyverman W. Lack of population genetic structuring in the marine planktonic diatom Pseudo-nitzschia pungens (Bacillariophyceae) in a heterogeneous area in the Southern Bight of the North Sea. Marine Biol. 2009;156:1149-58.

83. Casteleyn G, Leliaert F, Backeljau T, Debeer A-E, Kotaki Y, Rhodes L, Lundholm N, Sabbe K, Vyverman W. Limits to gene flow in a cosmopolitan marine planktonic diatom. Proc Natl Acad Sci. 2010;107:12952-7. 
84. Tesson SV, Borra M, Kooistra WH, Procaccini G. Microsatellite primers in the planktonic diatom Pseudo-nitzschia multistriata (Bacillariophyceae). Am J Bot. 2011;98:e33-e35.

85. Tesson SV, Montresor M, Procaccini G, Kooistra WH. Temporal changes in population structure of a marine planktonic diatom. PLoS One. 2014;9:e114984.

86. Evans KM, Chepurnov VA, Sluiman HJ, Thomas SJ, Spears BM, Mann DG. Highly differentiated populations of the freshwater diatom Sellaphora capitata suggest limited dispersal and opportunities for allopatric speciation. Protist. 2009; 160:386-96.

87. Godhe A, Sjöqvist C, Sildever S, Sefbom J, Harðardóttir S, Bertos-Fortis M, Bunse C, Gross S, Johansson E, Jonsson PR. Physical barriers and environmental gradients cause spatial and temporal genetic differentiation of an extensive algal bloom. J Biogeogr. 2016;43:1130-42. 